\title{
Giant intracardiac thrombosis in an infant with leukaemia and prolonged COVID-19 viral RNA shedding: a case report
}

\author{
Ehsan Aghaei Moghadam ${ }^{1,2}$, Shima Mahmoudi ${ }^{3,4}$, Alieh Safari Sharari ${ }^{5}$, Mehrnoush Afsharipour ${ }^{5}$, Mojtaba Gorji ${ }^{2}$,
} Amene Navaeian ${ }^{5}$, Azin Ghamari ${ }^{1}$ and Setareh Mamishi, ${ }^{3,6^{*}}$

\begin{abstract}
Background: COVID-19 can induce thrombotic disease both in the venous and arterial circulations, as a result of inflammation, platelet activation, endothelial dysfunction, and stasis. Although several studies have described the coagulation abnormalities and thrombosis in adult patients with COVID-19, there is limited data in children. Here, we present an 18-month-old boy with a prolonged SARS-CoV-2 RNA shedding and chronic right atrial and superior vena cava (SVC) thrombosis.

Case presentation: An 18-month-old boy with acute lymphoblastic leukemia (ALL) (pre-B cell ALL) and a history of chemotherapy was referred to our center due to intermittent fever with unknown origin. a positive nasopharyngeal PCR for COVID-19 was reported and stayed positive for eight consecutive weeks The high-resolution computed tomography $(\mathrm{HRCT})$ showed no sign of pulmonary embolism. Initial echocardiography indicated a semilunar thrombotic mass extending from right SVC into the right atrium without coronary or myocardial involvement. Enoxaparin was administered with continuous monitoring of the level of anti-Xa activity. The serial echocardiographic studies found a slow but continuous reduction in the mass size.

Conclusions: Our case shows that, as already described in adult patients, clinically relevant thrombosis can complicate the course of pediatric patients as well. In view of the specific and milder manifestations of COVID-19 in children, these complications may pose considerable diagnostic and therapeutic challenges.
\end{abstract}

Keywords: SARS-CoV-2, Children, Thrombosis, Acute lymphoblastic leukemia, Prolonged viral shedding

\section{Background}

The novel severe acute respiratory syndrome coronavirus 2 (SARS-CoV2), causing coronavirus disease in 2019 (COVID-19), has led to an unprecedented global health crisis.

\footnotetext{
* Correspondence: smamishi@sina.tums.ac.ir

${ }^{3}$ Pediatric Infectious Disease Research Center, Tehran University of Medical Sciences, Children's Medical Center Hospital, Dr. Gharib Street, Keshavarz Boulevard, Tehran, Iran

${ }^{6}$ Department of Infectious Diseases, Pediatrics Center of Excellence, Children's Medical Center, Tehran University of Medical Sciences, Tehran, Iran Full list of author information is available at the end of the article
}

Like adults, children can be affected by the coronavirus, but the presenting symptoms are usually milder. Prior studies have shown that angiotensin-converting enzyme II (ACE II) receptors act as a co-receptor for the virus entry into the cells [1]. This receptor has less affinity and maturity in children, which may result in children being less susceptible [2]. However, several studies have demonstrated that children can be affected by COVID19 [3, 4].

Although lung is the primary site of SARS-CoV2, the virus can disseminate to different organs and induce even atypical pathological conditions [5]. COVID-19 can

(c) The Author(s). 2021 Open Access This article is licensed under a Creative Commons Attribution 4.0 International License, which permits use, sharing, adaptation, distribution and reproduction in any medium or format, as long as you give appropriate credit to the original author(s) and the source, provide a link to the Creative Commons licence, and indicate if changes were made. The images or other third party material in this article are included in the article's Creative Commons licence, unless indicated otherwise in a credit line to the material. If material is not included in the article's Creative Commons licence and your intended use is not permitted by statutory regulation or exceeds the permitted use, you will need to obtain permission directly from the copyright holder. To view a copy of this licence, visit http://creativecommons.org/licenses/by/4.0/ The Creative Commons Public Domain Dedication waiver (http://creativecommons.org/publicdomain/zero/1.0/) applies to the data made available in this article, unless otherwise stated in a credit line to the data. 
induce both venous and arterial thrombosis, as well as myocardial injury, arrhythmia, and acute coronary syndrome, as a result of inflammation, platelet activation, endothelial dysfunction, and stasis [6-9].

Although several studies have described the coagulation abnormalities and thrombosis in adult patients with COVID-19, there is limited data in children. Here, we present an 18-month-old boy treated for acute lymphoblastic leukemia (ALL) with prolonged SARS- CoV-2 RNA shedding and chronic right atrial and superior vena cava (SVC) thrombosis.

\section{Case presentation}

An 18-month-old boy with pre-B cell ALL currently 3 weeks after the maintenance chemotherapy with vincristine PEG-asparaginase, methotrexate, doxorubicin and dexamethasone was referred to our center due to intermittent fever with unknown origin. Other symptoms included rash, diarrhea, vomiting, cough, or coryza. Physical examination revealed paleness without any specific symptom for infection. There was no other finding in favor of systemic or pulmonary embolism.

Laboratory tests revealed low level of white blood cell count, hemoglobin, and platelet. Our patient had elevated markers of thrombosis, inflammation, and cardiac injury. High levels of D-dimer (4000 pg/ml; day 6), fibrinogen $(647 \mathrm{mg} / \mathrm{dl}$; day 12$)$, and fibrin degradation product (FDP) (10 ng/ml; day 12) were observed. Lactate dehydrogenase (LDH) level was 1518, 1272, 866 and 622 $\mathrm{U} / \mathrm{L}$ at day $1,3,6$, and 12 , respectively. Moreover, elevated level of erythrocyte sedimentation rate (ESR) and C-reactive protein (CRP) were observed (Table 1).

The blood culture was positive for Pseudomonas Spp. Due to the patient's critical condition, antibiotic therapy was initiated with meropenem and vancomycin and continued for four weeks.

Nasopharyngeal samples were collected and tested for SARS-CoV-2 using the Reverse transcription polymerase chain reaction (rRT-PCR) assay according to the previous report [1]. Meanwhile, a positive nasopharyngeal PCR for COVID-19 was reported and stayed positive for eight consecutive weeks (Table 1). The high-resolution computed tomography (HRCT) showed no sign of pneumonia or pulmonary embolism. A portal venous catheter was implanted for anti-cancer therapy, and adequate anticoagulant therapy was administered after the diagnosis of the thrombosis was diagnosed.

Initial echocardiography indicated a semilunar thrombotic mass extending from right SVC into the right atrium without coronary or myocardial involvement (Fig. 1). The patient was a candidate for surgical mass removal due to increased risk for thromboembolic events; however, the intervention was postponed because of his unstable condition.

Table 1 Laboratory findings of the patient in different times

\begin{tabular}{|c|c|c|c|c|c|c|}
\hline & Day 1 & Day 3 & Day 6 & Day 12 & Day 40 & Day 60 \\
\hline White blood cell count $\left(\times 10^{9}\right.$ cells per $\left.\mathrm{L}\right)$ & 0.3 & 0.8 & 3.6 & 4.6 & 2.1 & 2.9 \\
\hline Neutrophil count $\left(\times 10^{9}\right.$ cells per $\left.\mathrm{L}\right)$ & - & - & 2.38 & 3.78 & 0.75 & 1.72 \\
\hline Lymphocyte count $\left(\times 10^{9}\right.$ cells per $\left.\mathrm{L}\right)$ & - & - & 0.18 & 0.19 & 0.61 & 0.44 \\
\hline Haemoglobin (g/dL) & 9.1 & 8.7 & 9.2 & 11.3 & 9.1 & 10.6 \\
\hline Platelet count $\left(\times 10^{9}\right.$ cells per $\left.\mathrm{L}\right)$ & 17 & 50 & 254 & 51 & 94 & 90 \\
\hline D-Dimer (pg/mL) & - & - & 4000 & - & 200 & - \\
\hline Fibrinogen (mg/dL) & - & - & - & 647 & 307 & - \\
\hline Interleukin 6 (pg/mL) & - & - & 257 & - & 98 & - \\
\hline Fibrin degradation product (FDP) (ng/ml) & - & - & - & 10 & 4 & - \\
\hline Erythrocyte sedimentation rate $(\mathrm{mm} / \mathrm{h})$ & 69 & - & - & 42 & 24 & - \\
\hline C-reactive protein (mg/L) & 52 & - & - & 75 & 26 & - \\
\hline Aspartate aminotransferase (U/L) & 53 & - & - & 13 & 24 & 19 \\
\hline Alanine aminotransferase $(\mathrm{U} / \mathrm{L})$ & 40 & - & - & 6 & 5 & 5 \\
\hline Lactate dehydrogenase (U/L) & 1518 & 1272 & 866 & 622 & - & - \\
\hline Creatinine $(\mu \mathrm{mol} / \mathrm{L})$ & 0.3 & 0.4 & 0.4 & 0.3 & 0.3 & 0.4 \\
\hline Prothrombin time (s) & - & - & 13.3 & - & 13.4 & - \\
\hline Partial thromboplastin time (s) & - & - & 30 & - & 43 & - \\
\hline International normalized ratio & - & - & 1.1 & - & 1.11 & - \\
\hline Blood culture & Positive & - & - & Negative & Negative & Negative \\
\hline SARS-CoV-2 rRT-PCR & - & Positive & - & Positive & Positive & Positive \\
\hline
\end{tabular}



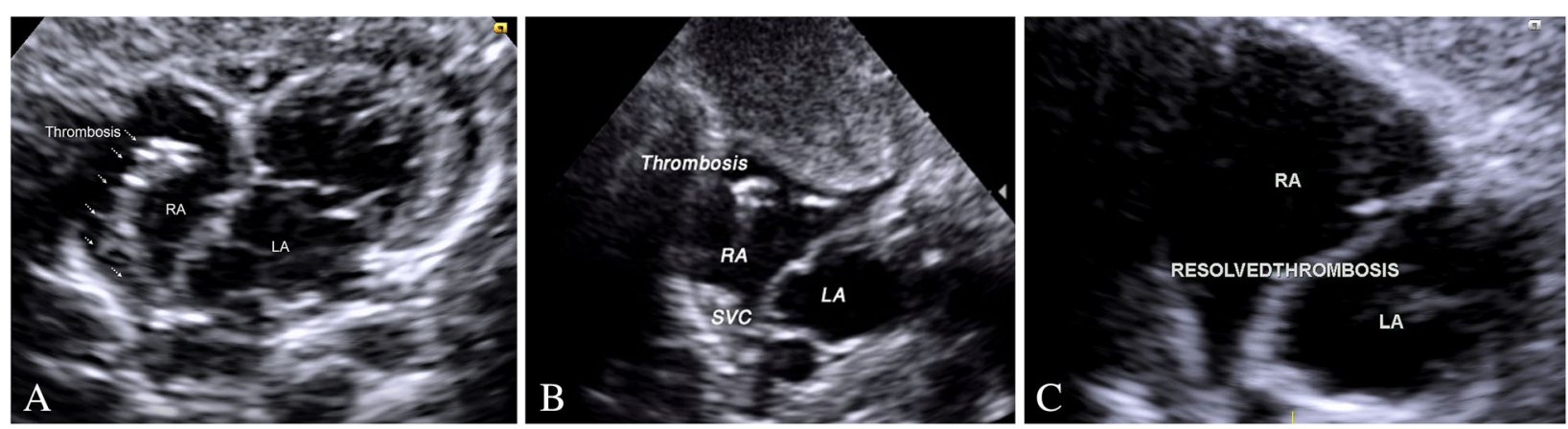

Fig. 1 Serial echocardiography a First echocardiography, crescentic thrombotic mass in the right atrium, b After 2 months of enoxaparin treatment, c Four-month follow-up. IVC: inferior vena cava, SVS: superior vena cava, RA: right atrium, LA: left atrium, LV: left ventricle, RV: right ventricle

Enoxaparin was administered with continuous monitoring of the level of anti-Xa activity. The serial echocardiographic studies found a slow but continuous reduction in the mass size (Fig. 1); therefore, surgical removal of the thrombosis was cancelled in favour of anticoagulation therapy with medical follow-up. After 4 months, follow-up echocardiography was performed and the result indicated that the thrombosis was completely resolved (Fig. 1).

Follow-up SARS-CoV-2 testing was performed on day $3,12,40$ and 60 with the goals of removing isolation precautions, and supporting appropriate discharge planning and all test were positive for SARS-CoV-2 nasopharyngeal rRT-PCR of SARS-CoV-2.

\section{Discussion and conclusions}

To the best of our knowledge, this is the first report describing giant intracardiac thrombosis following the COVID 19 infection in a child with ALL and prolonged SARS-CoV-2 RNA shedding.

Typically, SARS-CoV-2 RNA levels are detectable in the respiratory tract 2-3 days before symptoms onset, decline over the following 7-8 days and become nondetectable thereafter [10]. The time that viral RNA remains positive is not well understood. However, some studies have reported viral shedding for up to 3 months after resolve of symptoms [11-13].

Cancer patents are immunologically naive to this novel virus and are at risk of a more severe course of COVID19. They generally shed community-acquired respiratory viruses longer than immunocompetent people due to a constrained immune response $[14,15]$. In addition, the risk of thrombosis associated with ALL may add to that imposed by COVID-19. Lehners et al. reported the longterm virus detection for more than 30 days in $29 \%$ of infected patients with respiratory virus infections [14].

Our case had experienced a prolonged duration of viral shedding; however, it is unclear whether this represents infectious virus and poses a risk for forward transmission or not. Finally, we were unable to determine the exact duration of RT-PCR positivity in this case,

COVID-19 causes coagulation abnormalities in a proportion of patients, which can lead to thromboembolic events $[7,16]$. According to the latest Meta-analysis report [17], adult patients with severe COVID-19 infection had higher levels of D-dimer and fibrinogen and thrombo-inflammatory biomarkers including D-dimer, CRP, and LDH may predict the poor prognosis and severity of COVID-19 infection. Although a majority of patients with COVID-19 with coagulation abnormalities did not have the criteria of disseminated intravascular coagulation, diverse cardiovascular manifestations of COVID-19 observed [8]. Since our patient was not at risk for hypercoagulability due to the low platelet levels and bone marrow dysfunction, prolonged COVID-19 infection might be related to the persistent thrombosis.

The mechanisms of these coagulation abnormalities, following COVID-19 are unclear. However, severe inflammatory response as well as endothelial damage following COVID-19, particularly in cases with underlying comorbidities might predispose patients to a hypercoagulable conditions [18, 19].

Diagnosing of thrombosis may be more difficult in children with COVID-19 because of their milder clinical presentation. However, more research is needed in the prognostic value of monitoring the dynamics of coagulation parameters and ther prognostic value in pediatric patients as well, as shown in adult COVID-19 populations [20]. According to the consensus-based clinical recommendations, the use of anticoagulant thromboprophylaxis in hospitalized children with COVID-19-related infection is suggested [21]; however, more guidance is needed in determining the need and modalities of both prophylactic and therapeutic anticoagulation in pediatric patients [22].

Caution is needed when drawing implications from our case. Despite the prolonged duration of viral 
shedding in our case, we were unable to determine the exact duration of RT-PCR, nor whether this was associated with infectivity and risk for transmission. However, we should mention the limitation on the relative contribution of the three risk factors including ALL, COVID19 and, to a smaller extent, Pseudomonas infection.

In conclusion, our case shows that, as already described in adult patients, clinically relevant thrombosis can complicate the course of pediatric patients as well. In view of the specific and milder manifestations of COVID-19 in children, these complications may pose considerable diagnostic and therapeutic challenges.

\begin{abstract}
Abbreviations
SARS-CoV2: Severe acute respiratory syndrome coronavirus 2; COVID19: Coronavirus disease 2019; SVC: Superior vena cava; ALL: Acute lymphoblastic leukemia; rRT-PCR: Reverse transcription polymerase chain reaction; HRCT: High-resolution computed tomography
\end{abstract}

\section{Authors' contributions}

SM2 and AN managed the patient from infection and COVID-19 point of view. ASS managed the patient from the ALL point of view. MG and EAM managed the patient from the cardiology point of view. MA and AGH prepared the initial manuscript and SM1 revised it. All authors read and approved the final version of the manuscript.

\section{Funding}

No funding was available.

Availability of data and materials

All data obtained.

\section{Declarations}

Ethics approval and consent to participate

Not applicable.

\section{Consent for publication}

Not applicable.

\section{Competing interests}

The authors declare that they have no competing interests.

\section{Author details}

'Growth and Development Research Center, Tehran University of Medical Sciences, Tehran, Iran. ${ }^{2}$ Department of Pediatric Cardiology, Pediatrics Center of Excellence, Children's Medical Center, Tehran University of Medical Sciences, Tehran, Iran. ${ }^{3}$ Pediatric Infectious Disease Research Center, Tehran University of Medical Sciences, Children's Medical Center Hospital, Dr. Gharib Street, Keshavarz Boulevard, Tehran, Iran. ${ }^{4}$ Pediatrics Center of Excellence, Children's Medical Center, Tehran University of Medical Sciences, Tehran, Iran. ${ }^{5}$ Department of Pediatrics, Pediatrics Center of Excellence, Children's Medical Center, Tehran University of Medical Sciences, Tehran, Iran. ${ }^{6}$ Department of Infectious Diseases, Pediatrics Center of Excellence, Children's Medical Center, Tehran University of Medical Sciences, Tehran, Iran.

Received: 10 December 2020 Accepted: 27 April 2021

Published online: 12 May 2021

\section{References}

1. Mamishi S, Movahedi Z, Mohammadi M, Ziaee V, Khodabandeh M, Abdolsalehi MR, et al. Multisystem inflammatory syndrome associated with SARS-CoV-2 infection in 45 children: a first report from Iran. Epidemiol Infect. 2020;148:e196.

2. Dong Y, Mo X, Hu Y, Qi X, Jiang F, Jiang Z, et al. Epidemiology of COVID-19 among children in China. Pediatrics. 2020;145(6):e20200702.
3. Mamishi S, Heydari H, Aziz-Ahari A, Shokrollahi MR, Pourakbari B, Mahmoudi S, et al. Novel coronavirus disease 2019 (COVID-19) outbreak in children in Iran: atypical CT manifestations and mortality risk of severe COVID-19 infection. J Microbiol Immunol Infect. 2020:S1684-1182(20)30177-8.

4. Mahmoudi S, Mehdizadeh M, Badv RS, Navaeian A, Pourakbari B, Rostamyan M, et al. The coronavirus disease 2019 (COVID-19) in children: a study in an Iranian Children's Referral Hospital. Infect Drug Resist. 2020;13:2649.

5. Ekbatani M, Hassani S, Tahernia L, Yaghmaei B, Mahmoudi S, Navaeian A, et al. Atypical and novel presentations of coronavirus disease 2019: a case series of three children. Brit J Biomed Sci. 2021:78(1):47-52.

6. Klok F, Kruip M, Van der Meer N, Arbous M, Gommers D, Kant K, et al. Incidence of thrombotic complications in critically ill ICU patients with COVID-19. Thrombos Res. 2020;191:145-147.

7. Connors JM, Levy JH. COVID-19 and its implications for thrombosis and anticoagulation. . Blood J Am Soc Hematol. 2020;135(23):2033-40.

8. Nishiga M, Wang DW, Han Y, Lewis DB, Wu JC. COVID-19 and cardiovascular disease: from basic mechanisms to clinical perspectives. Nat Rev Cardiol. 2020;17(9):543-58.

9. Sperotto F, Friedman KG, Son MBF, VanderPluym CJ, Newburger JW, Dionne A. Cardiac manifestations in SARS-CoV-2-associated multisystem inflammatory syndrome in children: a comprehensive review and proposed clinical approach. Eur J Pediatrics. 2021:180(2):307-22.

10. Rhee C, Kanjilal S, Baker M, Klompas M. Duration of severe acute respiratory syndrome coronavirus 2 (SARS-CoV-2) infectivity. When is it safe to discontinue isolation? Clin Infect Dis. 2021:72(8):1467-74.

11. Xiao AT, Tong YX, Zhang S. Profile of RT-PCR for SARS-CoV-2: a preliminary study from 56 COVID-19 patients. Clin Infect Dis. 2020:71(16):2249-51.

12. Lan $L, X u D, Y e G$, Xia $C$, Wang $S$, Li Y, et al. Positive RT-PCR test results in patients recovered from COVID-19. JAMA. 2020;323(15):1502-3.

13. Sun J, Xiao J, Sun R, Tang X, Liang C, Lin H, et al. Prolonged persistence of SARS-CoV-2 RNA in body fluids. Emerg Infect Dis. 2020;26(8):1834

14. Lehners N, Tabatabai J, Prifert C, Wedde M, Puthenparambil J, Weissbrich B, et al. Long-term shedding of influenza virus, parainfluenza virus, respiratory syncytial virus and nosocomial epidemiology in patients with hematological disorders. PLoS One. 2016;11(2):e0148258.

15. von Lilienfeld-Toal M, Vehreschild JJ, Cornely O, Pagano L, Compagno F, Hirsch HH. Frequently asked questions regarding SARS-CoV-2 in cancer patients recommendations for clinicians caring for patients with malignant diseases. Leukemia. 2020:34(6):1487-94.

16. Bikdeli B, Madhavan MV, Jimenez D, Chuich T, Dreyfus I, Driggin E, et al. COVID-19 and thrombotic or thromboembolic disease: implications for prevention, antithrombotic therapy, and follow-up: JACC State-of-the-Art review. J Am Coll Cardiol. 2020;75(23):2950-73.

17. Chaudhary R, Garg J, Houghton DE, Murad MH, Kondur A, Chaudhary R, et al. Thrombo-inflammatory biomarkers in COVID-19: systematic review and metaanalysis of 17,052 patients. Mayo Clin Proc Innov Qual Outc. 2021;5(2):388-402.

18. Arachchillage DR, Laffan M. Abnormal coagulation parameters are associated with poor prognosis in patients with novel coronavirus pneumonia. J Thromb Haemost. 2020;18(5):1233-4.

19. Sun D, Li H, Lu X-X, Xiao H, Ren J, Zhang F-R, et al. Clinical features of severe pediatric patients with coronavirus disease 2019 in Wuhan: a single center's observational study. World J Pediatr. 2020;16(3):251-259.

20. Valerio L, Ferrazzi P, Sacco C, Ruf W, Kucher N, Konstantinides SV, et al. Course of D-Dimer and C-Reactive protein levels in survivors and nonsurvivors with COVID-19 pneumonia: a retrospective analysis of 577 patients. Thromb Haemost. 2021;121(01):098-101.

21. Goldenberg NA, Sochet A, Albisetti M, Biss T, Bonduel M, Jaffray J, et al. Consensus-based clinical recommendations and research priorities for anticoagulant thromboprophylaxis in children hospitalized for COVID-19related illness. J Thromb Haemost. 2020;18(11):3099-105.

22. Loi M, Branchford B, Kim J, Self C, Nuss R. COVID-19 anticoagulation recommendations in children. Pediatr Blood Cancer. 2020;67(9):e28485.

\section{Publisher's Note}

Springer Nature remains neutral with regard to jurisdictional claims in published maps and institutional affiliations. 